\title{
Endocuff-Assisted versus Cap-Assisted Colonoscopy Performed by Trainees: A Retrospective Study
}

Yutaka Okagawa, Tetsuya Sumiyoshi, Yusuke Tomita, Shutaro Oiwa, Fumihiro Ogata, Takashi Jin, Masahiro Yoshida, Ryoji Fujii, Takeyoshi Minagawa, Kohtaro Morita, Hideyuki Ihara, Michiaki Hirayama and Hitoshi Kondo

Department of Gastroenterology, Tonan Hospital, Sapporo, Hokkaido, Japan

Background/Aims: The adenoma detection rate ( $\mathrm{ADR})$ of screening colonoscopies performed by trainees is often lower than that of colonoscopies performed by experts. The efficacy of cap-assisted colonoscopy (CAC) in adenoma detection is well documented, especially that of CACs performed by trainees. Endocuff, a new endoscopic cap, is reportedly useful for adenoma detection; however, no trials have compared the efficacy of Endocuff-assisted colonoscopy (EAC) and CAC conducted by trainees. Therefore, the present study retrospectively compared the efficacy between EAC and CAC in trainees.

Methods: This was a single-center, retrospective study involving 305 patients who underwent either EAC or CAC performed by three trainees between January and December 2018. We evaluated the ADR, mean number of adenomas detected per patient (MAP), cecal intubation rate, cecal intubation time, and occurrence of complications between the EAC and CAC groups.

Results: The ADR was significantly higher in the EAC group than in the CAC group ( $54.3 \%$ vs. $37.3 \%, p=0.019)$, as was the MAP (1.36 vs. $0.74, p=0.003)$. No significant differences were found between the groups with respect to the cecal intubation rate or cecal intubation time. No major complications occurred in either group.

Conclusions: Our results suggest that EAC exhibits increased ADR and MAP compared to CAC when performed by trainees. Clin Endosc 2020;53:339-345

Key Words: Adenoma; Colonoscopy; Endocuff; Trainee

\section{INTRODUCTION}

Colorectal cancer is the second leading cause of cancer death worldwide, and its incidence is increasing. ${ }^{1}$ The removal of colon adenomas reduces colorectal cancer-related deaths, so it is important that colon adenomas are not missed during routine colonoscopy. ${ }^{2,3}$ A post-colonoscopy colorectal cancer (PCCRC) is a cancer detected after a negative screening colonoscopy, and the reported incidence of PCCRC is $6.0 \%-8.2 \%$

Received: June 24, 2019 Revised: September 5, 2019

Accepted: September 9, 2019

Correspondence: Yutaka Okagawa

Department of Gastroenterology, Tonan Hospital, North 4, West 7, Chuo-ku, Sapporo, Hokkaido 060-0004, Japan

Tel: +81-11-231-2121, Fax: +81-13-762-2753, E-mail: yutaka.okagawa@tonan. gr.jp

ORCID: https://orcid.org/0000-0002-1215-1901

(c) This is an Open Access article distributed under the terms of the Creative Commons Attribution Non-Commercial License (http://creativecommons.org/ licenses/by-nc/3.0) which permits unrestricted non-commercial use, distribution, and reproduction in any medium, provided the original work is properly cited. of all colorectal cancers. ${ }^{4,5}$ Moreover, it has been reported that around half of PCCRCs result from undetected lesions. ${ }^{6}$ Several reports have suggested that the adenoma detection rate (ADR) and mean number of adenomas detected per patient (MAP) are colonoscopy quality indicators because of their association with PCCRC. ${ }^{7,8}$ Colonoscopy trainees-not only have a low cecal intubation rate but also are more likely to exhibit incomplete inspection of the colonic mucosa, leading to missed colon adenomas. ${ }^{9,10}$ The use of a small plastic transparent cap attached to the tip of the colonoscope reportedly improved the cecal intubation rate and reduced the incidence of missed lesions. ${ }^{11-14}$ Additionally, cap-assisted colonoscopy (CAC) was reportedly more effective for the detection of polyps by colonoscopy trainees. ${ }^{14}$ Endocuff (Arc Medical Design Ltd., Leeds, England) is a new endoscopic cap made of a soft plastic material with two rows of flexible arms. This device stretches the colorectal lumen to enable enhanced viewing of the mucosa, resulting in fewer missed polyps hidden behind folds or in the corners of the colorectal lumen. The use 
of Endocuff in colonoscopy has been shown to improve the ADR compared to conventional colonoscopy (CC). ${ }^{15-18}$ Many studies have compared the efficacy of Endocuff-assisted colonoscopy (EAC) and CAC with CC; however, few studies have compared the usefulness of EAC and CAC. Recently, Sola-Vera et al. conducted a randomized study comparing EAC and $\mathrm{CAC}$ and concluded that there was no significant difference in $\mathrm{ADR}$ between the two groups. ${ }^{19}$ However, the experience level of the endoscopist was not discussed in detail in that study; thus, differences between EAC and CAC in trainees remain controversial. Thus, the aim of the present study was to retrospectively compare the efficacy between EAC and CAC performed by trainees.

\section{MATERIALS AND METHODS}

\section{Study design}

This was a single-center, retrospective case-control study conducted at Tonan Hospital, Sapporo, Japan. This study was approved by the institutional review board of Tonan Hospital and was conducted in accordance with the World Medical Association's Declaration of Helsinki.

\section{Patients}

Between January and December 2018, a total of 3,263 patients underwent colonoscopy at our hospital, of which 305 underwent either EAC or CAC performed by three trainees. Before undergoing EAC or CAC, all patients provided their written informed consent. The inclusion criteria were patients aged $\geq 20$ years undergoing colonoscopy due to a positive fecal immunochemical test, screening, surveillance after polypectomy, or evaluation of abdominal symptoms. The exclusion criteria were a history of colorectal surgery (excluding appendectomy), a history of inflammatory bowel disease (IBD), hereditary diseases such as Lynch syndrome and familial adenomatous polyposis, active gastrointestinal bleeding, severe colitis, and poor or inadequate bowel preparation according to the Aronchick scale. ${ }^{20}$

\section{Endoscopic procedures}

In the present study, trainees were defined as endoscopists who had performed $100-500$ colonoscopies. ${ }^{14,21}$ Prior to the study commencing, all trainees had performed more than 100 CACs and several EACs. Colonoscopies were performed using a high definition endoscope (CF-H290I, CF-HQ290I [Olympus Medical Systems, Tokyo, Japan], EC-590ZW/L, and EC600ZW/L [Fujifilm Co., Tokyo, Japan]) with $\mathrm{CO}_{2}$ insufflation. In the EAC and CAC groups, Endocuff (AEC120; Arc Medical Design Ltd.) and a transparent cap (M-03; Top Corporation,
Tokyo, Japan) were attached to the tip of the colonoscope, respectively. For each procedure, the trainee was responsible for the choice of colonoscope and selection of a transparent cap or Endocuff. Bowel preparation was performed using polyethylene glycol electrolyte solution with ascorbic acid (Moviprep; Ajinomoto, Tokyo, Japan) and magnesium citrate (Magcorol P; Horii Pharmaceutical Ind., Ltd, Osaka, Japan). All examinations were performed under conscious sedation using intravenous diazepam and pentazocine, and intravenous diazepam or midazolam was administered as required. Endoscopic observation and therapeutic interventions for detected polyps were performed during the withdrawal phase. The intubation and withdrawal times (excluding the time taken for therapeutic interventions) were measured using a stopwatch. If the patient complained of intolerable abdominal pain or the trainee did not achieve cecal intubation within $20 \mathrm{~min}$, an expert instead performed the intubation phase and the trainee performed the withdrawal phase. The intubation times of cases where the trainees did not achieve cecal intubation were excluded from the analysis.

\section{Polyps}

Polyps with a diameter $\geq 5 \mathrm{~mm}$, or those endoscopically diagnosed as neoplastic polyps by the trainee, were removed by endoscopic mucosal resection, hot snare polypectomy, or cold snare polypectomy. If the polyps were endoscopically diagnosed as hyperplastic polyps, or if the patients refused polyp removal, they were not resected. All detected polyps were evaluated with respect to location, size, and morphology. The polyp size was endoscopically measured using forceps as a guide. The morphology of polyps was classified according to the Paris classification. ${ }^{22}$ All removed polyps were pathologically examined, and classified as hyperplastic polyps, adenomas, cancers, or others. In the present study, the ADR was defined as the proportion of patients with at least one pathologically confirmed adenoma. Unresected adenomas diagnosed endoscopically were not reflected in the ADR.

\section{Outcome measures and statistical analysis}

The principal outcome of this study was the comparison of ADR between the EAC and CAC groups. The secondary outcome was the comparison of MAP, polyp detection rate (PDR; defined as the proportion of patients with at least one polyp including unresected polyps), cecal intubation rate, intubation time, and complications between the two groups. Quantitative variables are expressed as mean \pm standard deviation, while categorical variables are presented as total numbers and percentages. Categorical and continuous variables were analyzed using Pearson's chi-squared tests and Mann-Whitney $U$ tests, respectively. All $p$-values $<0.05$ were considered statistically 
significant.

\section{RESULTS}

\section{Patient characteristics}

A total of 305 patients underwent colonoscopy performed by three trainees between January and December 2018. Trainee A performed 94 colonoscopies in three months, trainee $\mathrm{B}$ performed 121 colonoscopies in four months, and trainee $\mathrm{C}$ performed 90 colonoscopies in three months. Of the 305 patients, 18 were excluded due to a history of colorectal surgery $(n=15)$, a history of IBD $(n=2)$, and inadequate bowel preparation $(n=1)$. Therefore, 94 and 193 patients who underwent EAC and CAC, respectively, were included in the analysis (Fig. 1). Evaluation of the patients' baseline characteristics showed no significant differences in age, sex, or indication for colonosco- py between the two groups (Table 1).

\section{Procedure-related outcomes}

There was no significant difference in the cecal intubation rate of the trainees between the EAC and CAC groups (93.6\% vs. $92.2 \%, p=0.849$ ). In cases where the trainee failed cecal intubation, an expert instead performed the intubation phase, and cecal intubation was ultimately achieved in all patients. The mean intubation times of the trainees in the EAC and CAC groups were 7.50 and $8.38 \mathrm{~min}$, respectively, and this difference was not significantly different $(p=0.081)$. Similarly, there was no significant difference in the mean withdrawal time between the EAC and CAC groups (9.52 min vs. 9.63 min, $p=0.167$ ) (Table 2).

\section{Polyp detection rate}

A total of 365 polyps were endoscopically detected: 167

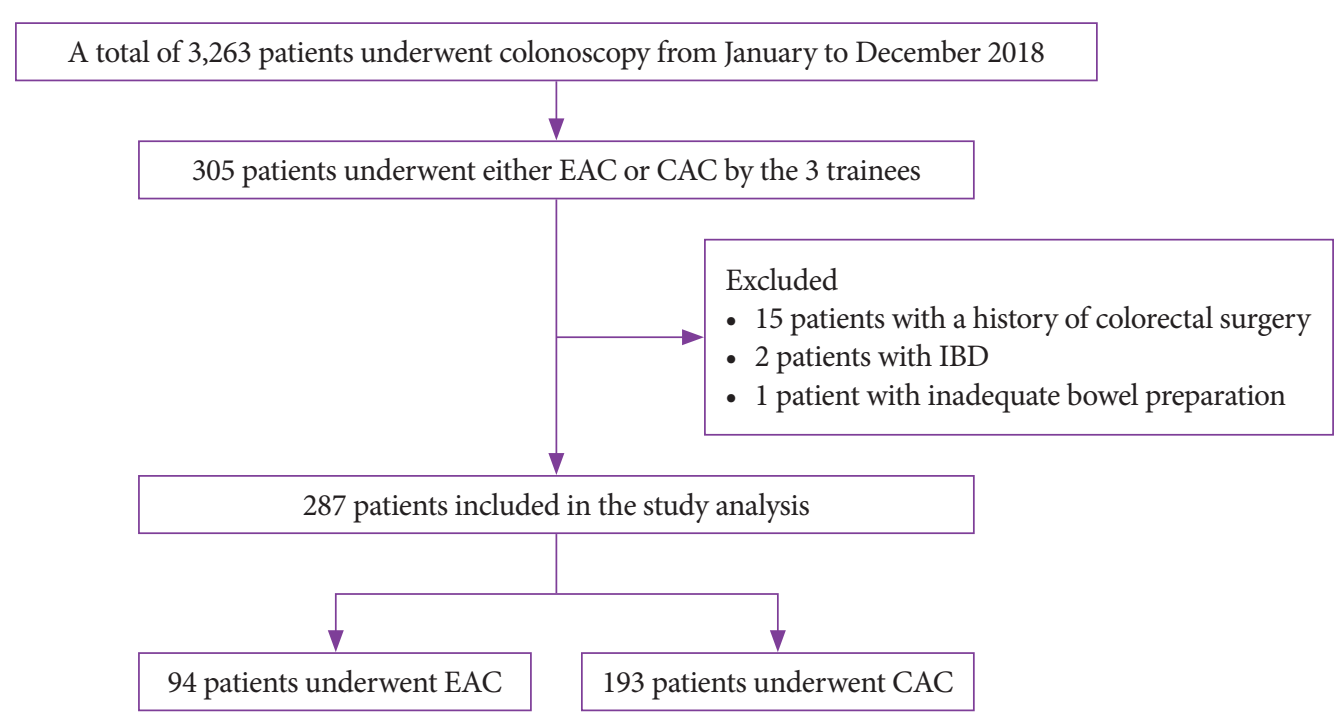

Fig. 1. Flow diagram of patient selection for the study. CAC, cap-assisted colonoscopy; EAC, Endocuff-assisted colonoscopy; IBD, inflammatory bowel disease.

Table 1. Patient Characteristics

\begin{tabular}{lccc}
\hline & EAC $(\boldsymbol{n = 9 4 )}$ & CAC $(\boldsymbol{n}=\mathbf{1 9 3})$ & \multicolumn{1}{c}{$\boldsymbol{p}$-value } \\
\hline Age (range) & $64.9 \pm 11.3(42-85)$ & $63.9 \pm 11.2(36-88)$ & 0.384 \\
Sex & $63(67.0 \%)$ & $107(55.4 \%)$ & 0.111 \\
Male & $31(33.0 \%)$ & $86(44.6 \%)$ & \\
Female & & & \\
Colonoscopy indication & $29(30.8 \%)$ & $49(25.4 \%)$ & 0.453 \\
FIT-positive & $48(51.1 \%)$ & $89(46.1 \%)$ & 0.496 \\
Screening & $12(12.8 \%)$ & $38(19.7 \%)$ & 0.341 \\
Polyp surveillance & $5(5.3 \%)$ & $17(8.8 \%)$ & 0.631 \\
Abdominal symptoms & & \\
\hline
\end{tabular}

CAC, cap-assisted colonoscopy; EAC, Endocuff-assisted colonoscopy; FIT, fecal immunochemical test. 
in the EAC group and 198 in the CAC group. The PDR was significantly higher in the EAC group than in the CAC group ( $66.0 \%$ vs. $51.8 \%, p=0.044)$. The mean number of polyps detected per patient was also higher in the EAC group (1.77 vs. $1.03, p=0.009)$. A total of 291 resected polyps $(79.7 \%$ of all polyps) were examined pathologically; 128 polyps in the EAC group and 143 in the CAC group were diagnosed as adenomas. One advanced colon cancer was found in the EAC group. There were 27 and 47 unresected polyps in the EAC and CAC groups, respectively (Table 3).

\section{Adenoma detection rate}

ADR was significantly higher in the EAC group than in the CAC group ( $54.3 \%$ vs. $37.3 \%, p=0.019)$. Although there was no significant difference in the ADR of each trainee between the two groups, it was higher in the EAC group than in the CAC group (trainee $\mathrm{A}, 55.9 \%$ vs. $38.5 \%, p=0.174$; trainee $\mathrm{B}, 57.9 \%$ vs. $41.8 \%, p=0.159$; trainee C, $50.0 \%$ vs. $30.6 \%, p=0.179$ ) (Table 3). Although we used colonoscopes from two companies in this study, there was no significant difference in the rate of scope selection (Olympus vs. Fujifilm; EAC, 37.2\% vs. 62.8\%; CAC, $33.2 \%$ vs. $66.8 \%, p=0.559$ ) or in ADR (Olympus vs. Fujifilm; EAC, $51.4 \%$ vs. $55.9 \%, p=0.716$; CAC, $39.1 \%$ vs. $36.4 \%, p=0.766$ ) between the two companies. The number of resected adenomas was 128 in the EAC group and 143 in the CAC group, and the MAP was significantly higher in the EAC group than in the CAC group (1.36 vs. $0.74, p=0.003$ ). Moreover, MAP of all colon segments was higher in the EAC group and significantly higher in the sigmoid colon in this group (Table 4). There was no significant difference in the mean size of detected adenomas between the EAC and CAC groups $(6.1 \mathrm{~mm}$ vs. $5.4 \mathrm{~mm}, p=0.088$ ). Similarly, when detected adenoma size was classified as $\leq 5 \mathrm{~mm},>5$ to $<10 \mathrm{~mm}$, and $\geq 10 \mathrm{~mm}$, there was no significant difference between the two groups. Additionally, there was no significant difference in the morphology of adenomas between the two groups (Table 4). Detachment of the Endocuff occurred in two cases; however, in both cases, the device was easily retrieved using forceps. There were no

Table 2. Colonoscopy Results

\begin{tabular}{lccc}
\hline & EAC & CAC & p-value \\
\hline Number of patients & 94 & 193 & \\
Withdrawal time (min) & $9.52 \pm 2.82$ & $9.63 \pm 2.35$ & 0.167 \\
Cecal intubation rate $(\%)$ & 93.6 & 92.2 & 0.849 \\
Cecal intubation achieved by trainee $(n)$ & 88 & 178 & \\
Cecal intubation time $(\mathrm{min})$ & $7.50 \pm 3.22$ & $8.38 \pm 4.02$ & 0.081 \\
\hline
\end{tabular}

CAC, cap-assisted colonoscopy; EAC, Endocuff-assisted colonoscopy.

Table 3. Polyp Detection Rate and Adenoma Detection Rate

\begin{tabular}{|c|c|c|c|}
\hline & $\operatorname{EAC}(n=94)$ & CAC $(n=193)$ & $p$-value \\
\hline Number of polyps & 167 & 198 & \\
\hline PDR & $66.0 \%(62 / 94)$ & $51.8 \%(100 / 193)$ & 0.044 \\
\hline Number of polyps per patient & $1.77 \pm 2.10$ & $1.03 \pm 1.30$ & 0.009 \\
\hline \multicolumn{4}{|l|}{ Histopathology of polyps } \\
\hline Adenoma & 128 & 143 & \\
\hline Hyperplastic polyp & 10 & 7 & \\
\hline Cancer & 1 & 0 & \\
\hline Other & 1 & 1 & \\
\hline Unresected polyps & 27 & 47 & \\
\hline $\mathrm{ADR}$ & $54.3 \%(51 / 94)$ & $37.3 \%(72 / 193)$ & 0.019 \\
\hline \multicolumn{4}{|l|}{ ADR per trainee } \\
\hline Trainee A & $55.9 \%(19 / 34)$ & $38.5 \%(20 / 52)$ & 0.174 \\
\hline Trainee B & $57.9 \%(22 / 38)$ & $41.8 \%(33 / 79)$ & 0.159 \\
\hline Trainee C & $50.0 \%(11 / 22)$ & $30.6 \%(19 / 62)$ & 0.179 \\
\hline
\end{tabular}

ADR, adenoma detection rate; CAC, cap-assisted colonoscopy; EAC, Endocuff-assisted colonoscopy; PDR, polyp detection rate. 
major complications, such as massive bleeding or perforation, in both groups.

\section{DISCUSSION}

Colonoscopy is a widely performed procedure used to prevent colorectal cancer. The ADR is considered the prime quality indicator of colonoscopy. ${ }^{7} \mathrm{ADR}$ of trainees is generally lower than that of experts ${ }^{23,24}$ and has been reported to be $23 \%-36 \%{ }^{25-27}$ Although a previous study reported no significant difference in ADR between $\mathrm{EAC}$ and $\mathrm{CAC},{ }^{19}$ differences between these procedures when performed by trainees remain unclear. In the present study, the cecal intubation rate and time were similar between the two groups. The Endocuff is bulkier than the transparent cap and has an attached flap, which did not prove to be difficult to insert as it was easily folded at the time of insertion. The ADR and MAP were significantly higher in the EAC group than in the CAC group in the present study. Our findings suggest that trainees were able to detect more adenomas because the Endocuff's flap caught the colon fold, indicating that fewer polyps were missed. Therefore, the Endocuff was more effective for adenoma detection, particularly in the sigmoid colon, which is an area that is often difficult to observe in detail due to flexion. Several studies showed that Endocuff improves the ADR of the sigmoid colon compared with $\mathrm{CC},{ }^{28,29}$ supporting our findings. Although there was no significant difference in the ADR of each trainee between the two groups, this result was thought to be influenced by the small number of patients. Several previous studies reported that compared to CC, colonoscopy using Endocuff improved $\mathrm{MAP}^{30,31}$ and resulted in a higher detection rate of polyps $<10 \mathrm{~mm}$ or of type Is morphology. . $^{28,29}$ In the present study, MAP was higher in the EAC group than in the CAC group, but no differences were noted in polyp size or morphology probably because this was a comparison between EAC and CAC, and not between EAC and CC, and CAC was also useful for polyp detection. In the present study, even though trainees were experienced in performing colonoscopies, ADR and MAP were relatively higher in both the EAC and CAC groups compared to the results of previous studies. ${ }^{25-27}$ However, we did not investigate ADR of CC, so it is unclear whether ADR improved compared to CC. Furthermore, because we did not investigate the efficacy of EAC and CAC performed by experts, differences between trainees and experts remain unclear. Cap detachment occurred in two cases in the EAC group, but it was easily retrieved using forceps. In both cases, cap detachment occurred at the time of with-

Table 4. The Mean Number of Adenomas Detected per Patient and Features of Detected Adenomas

\begin{tabular}{|c|c|c|c|}
\hline & $\mathrm{EAC}(n=94)$ & CAC $(n=193)$ & $p$-value \\
\hline Number of adenomas & 128 & 143 & \\
\hline MAP & $1.36 \pm 1.79$ & $0.74 \pm 1.30$ & 0.003 \\
\hline \multicolumn{4}{|l|}{ MAP of segment } \\
\hline Cecum & 0.13 & 0.05 & 0.494 \\
\hline Ascending colon & 0.20 & 0.16 & 0.499 \\
\hline Transverse colon & 0.30 & 0.16 & 0.220 \\
\hline Descending colon & 0.18 & 0.08 & 0.616 \\
\hline Sigmoid colon & 0.44 & 0.22 & 0.037 \\
\hline Rectum & 0.12 & 0.07 & 0.641 \\
\hline Size $($ mean \pm SD) & $6.1 \pm 4.3$ & $5.4 \pm 3.6$ & 0.088 \\
\hline$\leq 5 \mathrm{~mm}$ & $74(57.8 \%)$ & $99(69.2 \%)$ & 0.083 \\
\hline$>5$ to $<10 \mathrm{~mm}$ & $43(33.6 \%)$ & $34(23.8 \%)$ & 0.163 \\
\hline$\geq 10 \mathrm{~mm}$ & $11(8.6 \%)$ & $10(7.0 \%)$ & 0.820 \\
\hline \multicolumn{4}{|l|}{ Morphology } \\
\hline Ip & $8(6.3 \%)$ & $9(6.3 \%)$ & 0.995 \\
\hline Is & $86(67.2 \%)$ & $94(65.7 \%)$ & 0.836 \\
\hline IIa & $31(24.2 \%)$ & $39(27.3 \%)$ & 0.586 \\
\hline IIc & $3(2.3 \%)$ & $1(0.7 \%)$ & 0.815 \\
\hline
\end{tabular}

CAC, cap-assisted colonoscopy; EAC, Endocuff-assisted colonoscopy; MAP, mean number of adenomas detected per patient; SD, standard deviation. 
drawal of the scope from the anus. We, therefore, suggest that scope withdrawal from the anus should be performed carefully to prevent detachment of the Endocuff. Although not a cap-related complication, delayed bleeding after polypectomy occurred in one case in the EAC group. We could not evaluate the minor mucosal lacerations due to the retrospective design of the study, but no major complications such as massive bleeding or perforation were noted.

The present study has some limitations. First, this was a single-center, retrospective study with a small number of subjects. Because of the retrospective design, we could not investigate the patient's family history of colorectal cancer, which is known to be a risk factor of colorectal neoplasms. Furthermore, the body mass index and history of gynecologic surgery of each patient, which may affect the cecal intubation time and rate, were also unable to be investigated. ${ }^{32-34}$ In addition, more males were included in EAC group, although this was not statistically significant. In previous reports, it has been shown that the ADR of males is higher than that of females, ${ }^{35,36}$ so the male to female ratio in this study may have affected the ADR results. Second, the ADR may not be accurate as the unresected polyps were not pathologically evaluated. However, because the PDR and the mean number of polyps detected per patient were higher in the EAC group, we believe the ADR exhibited a similar trend. Third, it was difficult to evaluate the bowel preparation quality accurately due to the study's retrospective design. Therefore, we excluded patients with obviously inadequate bowel preparation as determined by reviewing the images. Fourth, each trainee performed colonoscopies for a different length of time, introducing potential selection bias.

In conclusion, to the best of our knowledge, this is the first study comparing the efficacy of EAC and CAC in trainees. The ADR and MAP of EAC were significantly higher than those of CAC, suggesting that EAC may be more useful than $\mathrm{CAC}$ when performed by trainees. A future, multicenter, randomized controlled trial is therefore required to further the results of this study.

Conflicts of Interest

The authors have no financial conflicts of interest.

\author{
Author Contributions \\ Conceptualization: Michiaki Hirayama, Hitoshi Kondo \\ Data curation: Yusuke Tomita, Shutaro Oiwa, Fumihiro Ogata \\ Formal analysis: Yutaka Okagawa \\ Investigation: YT, SO, FO, Takashi Jin, Masahiro Yoshida, Ryoji Fujii, \\ Takeyoshi Minagawa \\ Methodology: Kohtaro Morita, Hideyuki Ihara \\ Supervision: Tetsuya Sumiyoshi \\ Writing-original draft: $\mathrm{YO}$ \\ Writing-review\&editing: TS
}

ORCID

Tetsuya Sumiyoshi: https://orcid.org/0000-0002-9390-8477

Yusuke Tomita: https://orcid.org/0000-0002-2746-8020

Shutaro Oiwa: https://orcid.org/0000-0003-4415-0214

Fumihiro Ogata: https://orcid.org/0000-0001-6316-2144

Takashi Jin: https://orcid.org/0000-0003-3247-7527

Masahiro Yoshida: https://orcid.org/0000-0001-6071-6092

Ryoji Fujii: https://orcid.org/0000-0001-8209-2727

Takeyoshi Minagawa: https:/orcid.org/0000-0001-6425-3806

Kohtaro Morita: https://orcid.org/0000-0001-6325-5244

Hideyuki Thara: https://orcid.org/0000-0003-0490-6355

Michiaki Hirayama: https://orcid.org/0000-0002-1443-4526

Hitoshi Kondo: https://orcid.org/0000-0001-7612-5895

\section{REFERENCES}

1. Bray F, Ferlay J, Soerjomataram I, Siegel RL, Torre LA, Jemal A. Global cancer statistics 2018: GLOBOCAN estimates of incidence and mortality worldwide for 36 cancers in 185 countries. CA Cancer J Clin 2018;68:394-424.

2. Brenner H, Chang-Claude J, Seiler CM, Rickert A, Hoffmeister M. Protection from colorectal cancer after colonoscopy: a population-based, case-control study. Ann Intern Med 2011;154:22-30.

3. Zauber AG, Winawer SJ, O’Brien MJ, et al. Colonoscopic polypectomy and long-term prevention of colorectal-cancer deaths. N Engl J Med 2012;366:687-696.

4. Samadder NJ, Curtin K, Tuohy TM, et al. Characteristics of missed or interval colorectal cancer and patient survival: a population-based study. Gastroenterology 2014;146:950-960.

5. Corley DA, Jensen CD, Marks AR, et al. Adenoma detection rate and risk of colorectal cancer and death. N Engl J Med 2014;370:1298-1306.

6. Robertson DJ, Lieberman DA, Winawer SJ, et al. Colorectal cancers soon after colonoscopy: a pooled multicohort analysis. Gut 2014;63:949956.

7. Kaminski MF, Regula J, Kraszewska E, et al. Quality indicators for colonoscopy and the risk of interval cancer. N Engl J Med 2010;362:17951803.

8. Lee TJ, Rutter MD, Blanks RG, et al. Colonoscopy quality measures: experience from the NHS bowel cancer screening programme. Gut 2012;61:1050-1057.

9. Koch AD, Haringsma J, Schoon EJ, de Man RA, Kuipers EJ. Competence measurement during colonoscopy training: the use of self-assessment of performance measures. Am J Gastroenterol 2012;107:971-975.

10. Munroe CA, Lee P, Copland A, et al. A tandem colonoscopy study of adenoma miss rates during endoscopic training: a venture into uncharted territory. Gastrointest Endosc 2012;75:561-567.

11. Ng SC, Tsoi KK, Hirai HW, et al. The efficacy of cap-assisted colonoscopy in polyp detection and cecal intubation: a meta-analysis of randomized controlled trials. Am J Gastroenterol 2012;107:1165-1173.

12. Rastogi A, Bansal A, Rao DS, et al. Higher adenoma detection rates with cap-assisted colonoscopy: a randomised controlled trial. Gut 2012;61:402-408.

13. de Wijkerslooth TR, Stoop EM, Bossuyt PM, et al. Adenoma detection with cap-assisted colonoscopy versus regular colonoscopy: a randomised controlled trial. Gut 2012;61:1426-1434.

14. Kim DJ, Kim HW, Park SB, et al. Efficacy of cap-assisted colonoscopy according to lesion location and endoscopist training level. World J Gastroenterol 2015;21:6261-6270.

15. Williet N, Tournier Q, Vernet C, et al. Effect of Endocuff-assisted colonoscopy on adenoma detection rate: meta-analysis of randomized controlled trials. Endoscopy 2018;50:846-860.

16. González-Fernández C, García-Rangel D, Aguilar-Olivos NE, et al. 
Higher adenoma detection rate with the endocuff: a randomized trial. Endoscopy 2017;49:1061-1068.

17. De Palma GD, Giglio MC, Bruzzese D, et al. Cap cuff-assisted colonoscopy versus standard colonoscopy for adenoma detection: a randomized back-to-back study. Gastrointest Endosc 2018;87:232-240.

18. Chin M, Karnes W, Jamal MM, et al. Use of the Endocuff during routine colonoscopy examination improves adenoma detection: a meta-analysis. World J Gastroenterol 2016;22:9642-9649.

19. Sola-Vera J, Catalá L, Uceda F, et al. Cuff-assisted versus cap-assisted colonoscopy for adenoma detection: results of a randomized study. Endoscopy 2019;51:742-749.

20. Aronchick CA, Lipshutz WH, Wright SH, DuFrayne F, Bergman G. Validation of an instrument to assess colon cleansing. Am J Gastroenterol 1999;94:2667.

21. Massl R, van Putten PG, Steyerberg EW, et al. Comparing quality, safety, and costs of colonoscopies performed by nurse vs physician trainees. Clin Gastroenterol Hepatol 2014;12:470-477.

22. The Paris endoscopic classification of superficial neoplastic lesions: esophagus, stomach, and colon: November 30 to December 1, 2002. Gastrointest Endosc 2003;58(6 Suppl):S3-S43.

23. Baxter NN, Warren JL, Barrett MJ, Stukel TA, Doria-Rose VP. Association between colonoscopy and colorectal cancer mortality in a US cohort according to site of cancer and colonoscopist specialty. J Clin Oncol 2012;30:2664-2669.

24. Shaukat A, Oancea C, Bond JH, Church TR, Allen JI. Variation in detection of adenomas and polyps by colonoscopy and change over time with a performance improvement program. Clin Gastroenterol Hepatol 2009;7:1335-1340.

25. Klare P, Ascher S, Wagenpfeil S, et al. Trainee colonoscopists fulfil quality standards for the detection of adenomatous polyps. BMC Med Educ 2015;15:26.
26. Park SM, Lee SH, Shin KY, et al. The cap-assisted technique enhances colonoscopy training: prospective randomized study of six trainees. Surg Endosc 2012;26:2939-2943.

27. Gianotti RJ, Oza SS, Tapper EB, Kothari D, Sheth SG. A longitudinal study of adenoma detection rate in gastroenterology fellowship training. Dig Dis Sci 2016;61:2831-2837.

28. Floer M, Biecker E, Fitzlaff R, et al. Higher adenoma detection rates with endocuff-assisted colonoscopy - a randomized controlled multicenter trial. PLoS One 2014;9:e114267.

29. Biecker E, Floer M, Heinecke A, et al. Novel endocuff-assisted colonoscopy significantly increases the polyp detection rate: a randomized controlled trial. J Clin Gastroenterol 2015;49:413-418.

30. van Doorn SC, van der Vlugt M, Depla A, et al. Adenoma detection with Endocuff colonoscopy versus conventional colonoscopy: a multicentre randomised controlled trial. Gut 2017;66:438-445.

31. Pioche M, Matsumoto M, Takamaru H, et al. Endocuff-assisted colonoscopy increases polyp detection rate: a simulated randomized study involving an anatomic colorectal model and 32 international endoscopists. Surg Endosc 2016;30:288-295.

32. Henrikson NB, Webber EM, Goddard KA, et al. Family history and the natural history of colorectal cancer: systematic review. Genet Med 2015;17:702-712.

33. Anderson JC, Messina CR, Cohn W, et al. Factors predictive of difficult colonoscopy. Gastrointest Endosc 2001;54:558-562.

34. Nam JH, Lee JH, Kim JH, et al. Factors for cecal intubation time during colonoscopy in women: impact of surgical history. Saudi J Gastroenterol 2019;25:377-383.

35. Coe SG, Wallace MB. Assessment of adenoma detection rate benchmarks in women versus men. Gastrointest Endosc 2013;77:631-635.

36. Rex DK, Schoenfeld PS, Cohen J, et al. Quality indicators for colonoscopy. Gastrointest Endosc 2015;81:31-53. 